\title{
Inhibition of the renin-angiotensin system after acute myocardial infarction - treat first, select later?
}

\author{
Alistair S Hall, Rob Sapsford, Simon G Megarry, Stephen G Ball
}

To understand the observations of the randomised controlled clinical trials of angiotensin converting enzyme (ACE) inhibitor treatment following acute myocardial infarction, it is useful to consider first the scientific and clinical context in which they were performed. In 1987, the ACE inhibitors had just been shown to be effective, reducing mortality in patients with severe congestive cardiac failure. ${ }^{1}$ At the same time, aspirin and thrombolytic agents were becoming widely accepted as routine treatments for patients with acute myocardial infarction. ${ }^{2}$ Left ventricular dysfunction resulting from coronary artery thrombosis was also recognised as the most important predictor of worsening chronic congestive cardiac failure and long term mortality following acute myocardial infarction. ${ }^{3}$ Based on these key observations, and stimulated by both animal and human studies of ventricular remodelling (see earlier review), two distinct treatment strategies emerged. ${ }^{4}$

The first approach sought to treat a wide range of patients with suspected acute myocardial infarction in an attempt to limit the early pathological process of infarct expansion, and thereby attenuate subsequent progressive left ventricular dilatation and premature death. ${ }^{5}$ It was assumed that, as with administration of thrombolytic agents, the time from onset of symptoms to treatment initiation should be kept to a minimum, since dilatation began early. Four groups of investigators ${ }^{6-9}$ considered that treatment should be limited to four to six weeks unless signs and symptoms of heart failure emerged, while a fifth group elected to continue treatment long term in all randomised patients. ${ }^{10}$

A second investigational strategy opted to

Glossary of trials
AIRE study-Acute Infarction Ramipril Efficacy study
CCS-Chinese Captopril Study
CONSENSUS I-Cooperative New Scandinavian Enalapril
Survival Study
CONSENSUS II-Cooperative New Scandinavian Enalapril
Survival Study
GISSI-3-Gruppo Italiano per lo Studio della Supravvivenza
nell'infarcto Micardico
ISIS-4-Fourth International Study of Infarct Survival
SAVE-Survival and Ventricular Enlargement trial
SMILE-Survival of Myocardial Infarction Long term Evaluation
study
SOLVD-Studies of Left Ventricular Dysfunction
TRACE-The Trandolopril Cardiac Evaluation study

AIRE study-Acute Infarction Ramipril Efficacy study

CCS-Chinese Captopril Study

CONSENSUS I-Cooperative New Scandinavian Enalapril

CONSENSUS II-Cooperative New Scandinavian Enalapril

Survival Study

GISSI-3-Gruppo Italiano per lo Studio della Supravvivenza

SAVE-Survival and Ventricular Enlargement trial

SMILE-Survival of Myocardial Infarction Long term Evaluation

SOLVD-Studies of Left Ventricular Dysfunction

TRACE - The Trandolopril Cardiac Evaluation study target treatment by selecting those patients with evidence of either clinical heart failure or left ventricular dysfunction, as assessed by nuclear or ultrasound scanning. In three such studies, ${ }^{11-14}$ long term ACE inhibitor treatment was initiated once the early unstable phase of acute myocardial infarction and its initial treatment were complete. Each of the trials assessing this delayed/selective approach has reported a major impact on long term survival (table 1). In contrast, only two of the non-selective early intervention studies observed a statistically significant, albeit minor, beneficial effect on short term survival, although in each case statistical significance was lost with long term follow up (table 2).

Despite or perhaps because of the contrasting nature of results from the delayed/selective and early/non-selective trials, strong advocates have emerged for a compromise strategy (fig 1) in which treatment of most patients with suspected myocardial infarction is initiated early, continued for a short period of time, and then withdrawn except when clinical heart failure or an ejection fraction of less than $40 \%$ is observed..$^{15}$ In this article we caution against such an approach, arguing in favour of prospective, rather than retrospective, selection of patients for long term ACE inhibitor treatment.

\section{The CONSENSUS I and SOLVD heart \\ failure trials}

These trials recruited many patients with ischaemic heart disease, but on average many months to years after myocardial infarction. The CONSENSUS I trial compared the effects of giving either the ACE inhibitor enalapril or a matching placebo to patients with severe congestive cardiac failure. ${ }^{1}$ Clinical criteria were used to select patients who were then stabilised on digitalis and diuretic treatment before randomisation. The pretrial rationale was firmly based on the belief that sustained activation of the renin-angiotensin and sympathoadrenal neurohormonal axes might be contributing adversely to the heart failure syndrome. Several small studies had reported symptomatic benefit and improved exercise capacity from the use of ACE inhibitors added to treatment with digoxin and diuretics in patients with heart failure. ${ }^{16}$ Consequently, it was supposed that inhibition of the conversion of angiotensin I to angiotensin II might result also in an improved prognosis by mechanisms such as reducing salt and water retention and by attenuating angiotensin II receptor mediated vasoconstriction. Furthermore, there was some evidence to sug- 
Table 1 Major clinical trials assessing the effects ACE inhibitor treatment on all cause mortality in selected patients with suspected acute myocardial infarction (MI)

\begin{tabular}{|c|c|c|c|c|c|c|}
\hline Trial & Drug & $\begin{array}{l}\text { Number of } \\
\text { patients }\end{array}$ & $\begin{array}{l}\text { Patient } \\
\text { selection }\end{array}$ & $\begin{array}{l}\text { Planned } \\
\text { duration of } \\
\text { treatment }\end{array}$ & $\begin{array}{l}\text { Relative risk } \\
\text { reduction } \\
\text { (short term) }\end{array}$ & $\begin{array}{l}\text { Relative risk } \\
\text { reduction } \\
\text { (long term) }\end{array}$ \\
\hline SAVE" & Captopril & 2231 & \multirow{3}{*}{$\begin{array}{l}\text { EF }<40 \% \\
\text { No LVF } \\
\text { LVF } \\
\text { Anterior MI } \\
\text { No thrombolysis } \\
\text { WMI }<1 \cdot 2\end{array}$} & Indefinite & (NS) & $\underline{19 \%}$ \\
\hline $\begin{array}{l}\text { AIRE }^{12} \\
\text { SMILE }^{8}\end{array}$ & $\begin{array}{l}\text { Ramipril } \\
\text { Zofenopril }\end{array}$ & $\begin{array}{l}1986 \\
1556\end{array}$ & & $\begin{array}{l}\text { Indefinite } \\
42 \text { days }\end{array}$ & $\begin{array}{l}\text { (NS) } \\
\underline{\text { NS }}\end{array}$ & $\frac{27 \%}{(29 \%)}$ \\
\hline TRACE $^{13}$ & Trandolopril & 1749 & & Indefinite & (NS) & $\underline{22} \%$ \\
\hline
\end{tabular}

EF, ejection fraction; LVF, left ventricular failure.

Primary end points are underlined while subsidiary end points are in brackets. All four trials observed major effects on long term survival, though in the SMILE study this was not the predetermined primary end point. Major effects on mortality were seen by 30 days in AIRE and TRACE, though they were at the limit of conventional levels of statistical significance (see table 3).

Table 2 Major clinical trials assessing the effects ACE inhibitor treatment in relatively unselected patients with suspected acute myocardial infarction

\begin{tabular}{|c|c|c|c|c|c|c|}
\hline Trial & Drug & $\begin{array}{l}\text { Number of } \\
\text { patients }\end{array}$ & $\begin{array}{l}\text { Patient } \\
\text { selection }\end{array}$ & $\begin{array}{l}\text { Planned } \\
\text { duration of } \\
\text { treatment }\end{array}$ & $\begin{array}{l}\text { Relative risk } \\
\text { reduction } \\
\text { (short term) }\end{array}$ & $\begin{array}{l}\text { Relative risk } \\
\text { reduction } \\
\text { (long term) }\end{array}$ \\
\hline $\begin{array}{l}\text { CONSENSUS II }{ }^{10} \\
\text { GISSI- } 3^{7} \\
\text { ISIS-4 }^{6} \\
{\text { CSS }-1^{9}}^{9}\end{array}$ & $\begin{array}{l}\text { Enalapril } \\
\text { Lisinopril } \\
\text { Captopril } \\
\text { Captopril }\end{array}$ & $\begin{array}{r}6090 \\
19394 \\
58050 \\
11345\end{array}$ & $\begin{array}{l}\text { "all" } \\
\text { "all" } \\
\text { "all" } \\
\text { "all" }\end{array}$ & $\begin{array}{l}\text { Indefinite } \\
42 \text { days } \\
30 \text { days } \\
28 \text { days }\end{array}$ & $\begin{array}{l}\text { NS) } \\
\frac{11 \%}{7 \%} \\
\underline{\mathrm{NS}}\end{array}$ & $\begin{array}{l}\text { NS } \\
\text { (NS) } \\
\text { ? }\end{array}$ \\
\hline
\end{tabular}

Primary end points are underlined while subsidiary end points are in brackets. The GISSI-3 and ISIS-4 trials reported a small short term benefit which became statistically non-significant at 6 months and 12 months respectively.

gest that inhibition of ACE might have beneficial effects on cardiac ischaemia and arrhythmic tendencies, possibly mediated by potentiation of bradykinin. ${ }^{17} 18$

In the early part of this first ACE inhibitor mortality trial, a significant incidence of "first dose" hypotension was observed, necessitating a protocol amendment with the introduction of a less vigorous stepwise titration regimen. Following six months of treatment there was a significant difference in the number of deaths observed for patients randomised to receive treatment with placebo (55 deaths; mortality $44 \%$ ) as compared to the enalapril (33 deaths; mortality 26\%). Consequently, the Safety Monitoring Committee stopped the trial prematurely as they deemed it unethical to withhold active treatment from patients receiving placebo.

Although the CONSENSUS I trial was rela-

"All" patients
Withdraw
Withdraw
Patient selection before treatment
4-6 weeks
Acute myocardial infarction
Figure 1 Three alternative strategies for the
administration of $A C E$ inhibitor ttreatment following acute
myocardial infarction (AMI) are depicted. The first
approach is to treat -all" patients with suspected AMI for
four to six weeks and then stop (assessed in the ISIS-4,
GISSI-3, ${ }^{7}$ and CCS-19 trials). A suggested modification
of this first policy is to select some patients for ongoing
treatment beyond six weeks (not assessed in trials). Finally,
patients may be selected before initiation of long term
treatment (assessed in AIRE, ${ }^{2}$ SAVE, ${ }^{11}$ and TRACE ${ }^{13}$
studies).

tively small (253 patients), it had a major clinical impact. Perhaps the strongest indicator of this is that most subsequent trials excluded patients with severe congestive cardiac failure on the grounds that potential randomisation to placebo would be unethical. The SOLVDTreatment trial of enalapril in patients with a reduced ejection fraction and mild to moderate congestive cardiac failure also included approximately 60 patients with a grade IV New York Heart Association (NYHA) classification. ${ }^{19}$ Of these, $64 \%$ randomised to placebo and $65 \%$ randomised to enalapril had died by the close of the trial. This apparent lack of benefit will certainly have been influenced by the small number of patients and possibly by the longer duration of follow up. Taking the study as a whole, 58 fewer deaths (risk reduction 16\%; $95 \%$ confidence interval $5 \%$ to $26 \% ; \mathrm{P}=$ 0.004 ) occurred in patients randomised to enalapril as compared to placebo.

Patients screened by the SOLVD investigators with a reduced ejection fraction who were not receiving vasodilator, digitalis, or diuretic treatments for heart failure were stratified into the SOLVD-Prevention trial and randomised to either enalapril or placebo. ${ }^{20}$ Many of these patients were asymptomatic (67\% were NYHA grade I), although this was not an entry requirement. Despite similar mean ejection fractions at entry into the study, patients in the SOLVDPrevention trial had a much better prognosis than those in SOLVD-Treatment. Possibly as a result of this, the effect of enalapril on all cause mortality was small and statistically non-significant $(P=0 \cdot 3)$. However, after combining all cause mortality with the end point of worsening heart failure, a statistically significant benefit was observed ( $P=0.001)$.

\section{The CONSENSUS II and SAVE postinfarction trials}

The simultaneous publication of the CONSENSUS II and SAVE trials in 1992 showed dramatically the ongoing clinical and scientific 
uncertainty regarding the appropriate use of the ACE inhibiting drugs following acute myocardial infarction. ${ }^{1011}$ The CONSENSUS II trial observed a trend towards harm ( $P=$ $0 \cdot 3$ ) following early intravenous and later oral administration of enalapril. However, in contrast to the SOLVD-Prevention trial which reported an identical $P$ value for all cause mortality, no combined end point analyses were reported. An increased incidence of profound hypotension was clearly apparent, being proposed as a possible cause of the overall lack of benefit even after six months of treatment. ${ }^{21}$

In contrast to both the SOLVD-Prevention and CONSENSUS II trialists, the SAVE investigators were able to report a convincing reduction in all cause mortality (risk reduction $19 \%$; CI $3 \%$ to $32 \% ; \mathrm{P}=0.019$ ) for patients with asymptomatic left ventricular dysfunction (EF $<40 \%$ ) following acute myocardial infarction, when treated long term with the ACE inhibitor captopril started on average 11 days after the heart attack. ${ }^{11}$ Target dosages of $50 \mathrm{mg}$ three times daily were achieved and tolerated in the majority of patients, and the later need for open label treatment was also reduced. However, as well as clear beneficial effects on survival and the later development of overt heart failure, a more controversial effect of captopril on reinfarction was also reported. ${ }^{22}$

\section{The AIRE study}

In 1993, with a climate of ongoing clinical and scientific uncertainty, the AIRE (Acute Infarction Ramipril Efficacy) study investigators reported their findings. ${ }^{12}$ Patients with either transient or ongoing clinical evidence of heart failure (in the opinion of the attending physician) were randomised to receive either ramipril or placebo from the second day after definite myocardial infarction. Patients with severe heart failure were not entered. After an average follow up period of 15 months, patients randomised to ramipril treatment had a significantly lower risk of dying (risk reduction $27 \% ; 95 \%$ CI $11 \%$ to $40 \% ; \mathrm{P}=0.002$ ). Furthermore, and in contrast to the SAVE trial, this effect was clearly apparent by 30 days. As in the SOLVD and SAVE trials, patients receiving treatment with a diuretic at the time of randomisation appeared to derive the greatest benefit from treatment. Also consistent with earlier studies was the observation that progression to more severe grades of heart failure was significantly reduced. However, in contrast with the longer term SAVE and SOLVD trials, no clear benefit on reinfarction was apparent.

\section{Meta-analysis and the ISIS-4, GISSI-3 and CCS-1 "mega-trials"}

Three trials planning to recruit a total of up to 100000 patients were just starting when the results of SAVE and CONSENSUS II were first presented. To counter suggestions that these investigations should not proceed, the following arguments were made: (1) in con- trast to CONSENSUS II, the ISIS-4, GISSI-3 and CCS-1 trials would not initiate treatment intravenously; (2) learning from CONSENSUS II, greater caution would be exercised in patients with already low blood pressures; (3) ACE inhibitors other than enalapril would be tested; (4) the greater size of the "mega-trials" would provide a more accurate measure of potential benefits and risks.

ISIS- 4 and CCS- 1 evaluated the effects of captopril or placebo started within 24 hours and continued for one month, in patients with suspected acute myocardial infarction. The GISSI-3 trialists gave open label lisinopril (no placebo) for six weeks to a similar group of patients. Observed reductions in the risk of death were $7 \%(95 \%$ CI $1 \%$ to $13 \% ; \mathrm{P}=$ $0.02), 5 \%$ (95\% CI not reported; $P=N S$ ), and $11 \%(95 \%$ CL $21 \%$ to $1 \% ; P=0.03)$ for the ISIS-4, CCS-1, and GISSI-3 trials, respectively. Combined in a meta-analysis with CONSENSUS II and 11 smaller trials, the observed risk reduction was $6.5 \%$ (95\% CI $2 \%$ to $11 \% ; P=0.01$ ). Expressed in absolute terms, there were 4.6 deaths prevented/ delayed for every 1000 patients who were treated for one month. However, these small effects were not statistically significant at 28 days (CCS-1), ${ }^{9}$ six months (GISSI-3), ${ }^{723}$ and one year (ISIS-4). ${ }^{6}$

\section{The SMILE and TRACE studies}

The concepts of infarct expansion and progressive ventricular dilatation which formed the rationale for the early intervention trials were based on experiments usually carried out in dogs and rats, in addition to small morbidity trials performed in the prethrombolytic era. ${ }^{24-26}$ In all these instances, regional infarction of the full thickness of the left ventricular free wall was predominant. Influenced by these data, the SMILE and TRACE investigators selected patients in whom similar types of infarction were likely to be present. ${ }^{81314}$ In SMILE, only patients with anterior $Q$ wave infarction who were not treated with systemic thrombolysis were selected for the study. The reasons why thrombolysis was not given have not been reported, though they will certainly have included relative contraindications such as late presentation. Consequently, this investigation may have more in common with trials of a delayed/selective, compared to an early/ non-selective, treatment strategy. The ACE inhibitor zofenopril was started within 24 hours of admission, continued for six weeks, and then actively withdrawn. At that time zofenopril had a beneficial effect on a combined end point of death or congestive cardiac failure (risk reduction $34 \%$; $95 \%$ CI $8 \%$ to $54 \% ; P=0.018$ ) though not on all cause mortality independent of the occurrence of heart failure. After one year of post hoc open follow up, survival was significantly greater for zofenopril treated patients (risk reduction $29 \% ; 95 \%$ CI $6 \%$ to $51 \% ; P=0.011)$.

In the TRACE trial, regional left ventricular infarction was identified by echocardiographic determination of a wall motion index (WMI ${ }^{13}$ 
of $<1 \cdot 2$. This corresponds to an ejection fraction of approximately 35\% - though, importantly, the two measures are not fully interchangeable. TRACE included many high risk patients who appear to have been excluded from other investigations including both AIRE and SAVE. Administration of the ACE inhibitor trandolopril produced a significant improvement in long term survival (risk reduction $22 \% ; 95 \% ; P=0.0014$ ), the benefit being apparent within weeks of starting treatment. $^{14}$

\section{From trials to practice}

When of an adequate size and appropriately conducted, a randomised controlled trial has great potential to influence daily clinical practice. ${ }^{27}$ This is particularly true when a large, statistically reliable benefit is seen to occur in a readily identifiable group of patients. The SAVE, AIRE, SMILE, and TRACE trials reported long term relative risk reductions of $20 \%$ or greater, while meta-analysis of the CONSENSUS I, ISIS-4, GISSI-3, and CCS-1 trials revealed a short term benefit in the region of $5 \%$. Because the inclusion criteria to the first set of trials contrasted with the second set by being overtly selective, it is suggested that benefit to a minority of patients is diluted by lack of benefit to the majority entered into the "mega-trials". ${ }^{28}$ If this were not true, an alternative explanation might be that the molecular characteristics or dosages of ACE inhibitors used in SAVE, AIRE, SMILE, and TRACE were somehow superior. However, this second hypothesis currently has little support. ${ }^{29}$ It has also been suggested that if patients in the ISIS-4, GISSI-3, and CCS-1 trials had continued to receive long term therapy, more convincing benefits might have emerged (fig 2).

The published protocols of the ISIS- 4 and

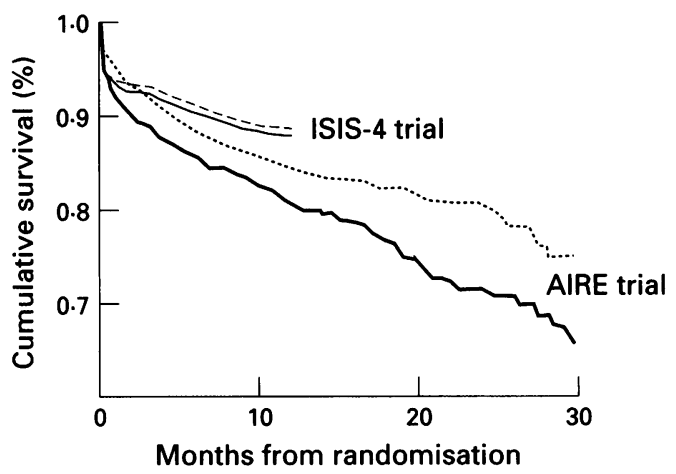

Figure 2 Cumulative survival estimates for the ISIS-4 (short duration of treatment) and AIRE (long duration of treatment) studies. It can clearly be seen that while the ISIS-4 curves remain minimally separated and parallel, the AIRE curves are widely separated and continue to diverge with time. These and other similar observations (GISSI-3 and CCS-1 like ISIS-4; TRACE and SAVE like AIRE) are cited as evidence in favour of the need for long term treatment in selected patients after acute
myocardial infarction. AIRE survival estimates are derived from original data whilst ISIS-4 estimates have been redrawn based on the original publication. ${ }^{6}$ (Dashed lines represent ACE inhibitor treatment; solid lines represent placebo treatment.)
GISSI- 3 trials $^{67}$ indicate that after four to six weeks, the study treatment was to be withdrawn, unless there was a clinical indication to continue. An unspecified number of patients with heart failure and/or reduced ejection fractions should therefore have received long term treatment in the light of the findings of other trials. The presumed effect of this strategy would be to produce similar mortality rates in each of the randomised groups of patients from the time of withdrawal onwards. Alternatively, anticipated beneficial structural effects of early intervention might be reflected in improved long term survival rates for treated as compared to control patients. However, as the survival curves in ISIS-4 remained parallel, and those of the GISSI- 3 trial converged following treatment withdrawal, the need for long term treatment is emphasised (fig 2).

After only 30 days of treatment in AIRE and TRACE, large relative risk reductions consistent with long term findings were already apparent. Even in the absence of any additional "first day" benefit claimed by the early intervention trials, ${ }^{15}$ it would appear that prospective selection of patients produces a much better risk/benefit ratio despite equivalent placebo mortality and duration of treatment (table 3). Furthermore, absolute benefits, measured either as the number of deaths prevented per thousand patients treated or as additional length of life gained, became greater over time, presumably as a result of continued treatment (fig 2).

Profound hypotension in the initial hours of acute myocardial infarction has long been recognised as a cause of subendocardial infarct extension. ${ }^{30}$ However, in the post-thrombolytic era the possibility that it may also result in infarct completion or extension is plausible. ${ }^{31}$ Reperfusion of a vessel with a ruptured critical coronary artery stenosis, once achieved by aspirin and thrombolysis, may be reversed by profound hypotension. This would explain the excess of patients with confirmed infarction (5/1000 patients treated; $P<0.01)$ or cardiogenic shock $(5 / 1000$ patients treated; $P<$ 0.01 ) which occurred in the ISIS-4 trial during the initial hospital admission. Similarly, underperfusion of the kidney because of profound hypotension (99/1000 patients treated; $\mathrm{P}<0.001)$ might explain the significant excess of renal failure ( 5 cases $/ 1000$ patients treated; $P$ $<0.01)$.

\section{The "Treat first, select later" policy}

Even if early treatment of most patients was to be accepted as a generally safe option, this would not preclude inducing harm in some. When net benefit attributed to a treatment strategy is small, then the likelihood of any individual patient experiencing benefit is likely to be similar to that of experiencing harm. However, when the net benefit observed with a treatment strategy is large, then for an individual patient the chance of risk reduction must compare more favourably with the probability of risk production. 
Table 3 Published effects of ACE inhibitor treatment on short term mortality in different clinical trials

\begin{tabular}{|c|c|c|c|c|c|}
\hline Trial & $\begin{array}{l}\text { Time from } \\
\text { randomisation } \\
\text { (days) }\end{array}$ & $\begin{array}{l}\text { Mortality for } \\
\text { control } \\
\text { group }\end{array}$ & $\begin{array}{l}\text { Mortality for } \\
\text { treatment } \\
\text { group }\end{array}$ & $\begin{array}{l}\text { Deaths prevented/ } \\
\text { delayed } \\
\text { per } 1000 \text { treated }\end{array}$ & $\begin{array}{l}\text { Statistical } \\
\text { significance }\end{array}$ \\
\hline \multicolumn{6}{|c|}{ Non-selective trials: } \\
\hline ISIS-4 ${ }^{6}$ & 35 & $7 \cdot 7 \%$ & $7 \cdot 2 \%$ & 5 & $2 \mathrm{P}=0.02$ \\
\hline CCS $-1^{9}$ & 28 & $9 \cdot 6 \%$ & $9 \cdot 1 \%$ & 5 & $2 \mathrm{P}=0.30$ \\
\hline GISSI-37 & 42 & $7 \cdot 1 \%$ & $6 \cdot 3 \%$ & 8 & $2 P=0.03$ \\
\hline \multicolumn{6}{|l|}{ Selective trials: } \\
\hline SMILE $^{8}$ & 42 & $6 \cdot 5 \%$ & $4.9 \%$ & 16 & $2 \mathrm{P}=0 \cdot 19$ \\
\hline AIRE $^{12}$ & 30 & $7 \cdot 7 \%$ & $5 \cdot 6 \%$ & 21 & $2 P=0.05$ \\
\hline
\end{tabular}

As well as wanting substantially better odds of deriving benefit rather than harm, an individual patient will wish to obtain benefit which is either sustained or increased with time. This was observed for SAVE, AIRE, TRACE, and SMILE, but not CONSENSUS II, ISIS-4, or GISSI-3. Consequently, it has been suggested-to ensure no suitable patients are missed-that during the first month after acute myocardial infarction treatment should follow the non-selective pattern of the ISIS-4 and GISSI- 3 trials, switching thereafter to the selective approach of the SAVE, SMILE, AIRE, and TRACE studies. This policy of retrospective selection has a number of important flaws which should be considered carefully by those who choose this approach.

First and most importantly, none of the eight large scale trials of ACE inhibitor treatment after acute myocardial infarction assessed a "treat first, select later" strategy. Second, it is naive to imagine that the two strategies can be combined to maximise the benefits of each. For example, it is wrong to believe that patients can be selected for withdrawal of treatment after one month based on a normal ejection fraction/wall motion index and the absence of clinical heart failure. One month of treatment with an ACE inhibitor would be expected to treat, and thereby mask, clinical heart failure and left ventricular dysfunction. The "treat first, select later" policy may therefore withhold long term treatment and benefits from patients who would have obtained them based on the prospective selection strategy of the AIRE, SAVE, TRACE, and SMILE trials.

Similarly, it may also be incorrect to assume that withdrawal of ACE inhibition is without any potential hazards. ${ }^{31}$ After six weeks of treatment in the GISSI- 3 trial, there was a net benefit of eight deaths delayed/prevented per 1000 patients treated. Four and one half months after treatment withdrawal, this benefit was reduced to four deaths delayed/prevented by lisinopril. Consequently, there must have been an excess of four deaths per 1000 in those patients withdrawn from lisinopril. ${ }^{23} \mathrm{At}$ a time when treatment benefits were expected to increase, this excess is particularly remarkable and certainly does not exclude the possibility of a harmful effect of treatment withdrawal. Possible mechanisms by which an adverse effect of treatment withdrawal may be mediated have previously been reviewed in detail. ${ }^{31}$

Finally, the question as to whether ACE inhibitors can reduce myocardial reinfarction should be addressed. In our view and that of others, this issue has not been resolved..$^{22}$ The data are certainly consistent with a moderate beneficial effect (about $10 \%$ relative risk reduction) which may be clinically important. If later trials confirm this hypothesis, then the long term prescription of ACE inhibitors after acute myocardial infarction may need to be extended to a much greater number of patients. Certainly any effect does not appear to be occurring within the first 30 days of treatment, as neither GISSI-3 nor ISIS-4 observed a reduction in the rate of reinfarction. Consequently, speculation of this sort should not be used to justify a "treat first, select later" policy.

\section{Conclusion}

ACE inhibitors clearly have an important role to play in the long term treatment of selected patients after acute myocardial infarction. Used appropriately, these agents produce improvements in survival and progression of heart failure which are comparable to those seen following treatment with thrombolytic agents and aspirin. However, the magnitude of benefit is much greater in selected groups of patients, such as those manifesting signs of heart failure or left ventricular dysfunction, than for the remaining majority. All investigators from the major trials agree on the appropriateness of selecting patients before long term treatment, though they disagree on the timing and conditions for such a selective process. The results of four trials which applied prospective selection criteria are independently and collectively convincing. ${ }^{811-13}$ In contrast, four trials which failed to assessand yet recommended-a strategy of retrospective selection of patients following one month of treatment are far from convincing, either independently or in combination. ${ }^{69} \mathrm{It}$ is a major irony that following such a concerted international research effort, clinicians are advised to routinely adopt an untested and counterintuitive "treat first, select later" strategy. ${ }^{15}$ Evaluation of individual patient characteristics before rather than after a treatment decision is surely most appropriate.

1 The CONSENSUS Trial Study Group. Effects of enalapri on mortality in severe congestive heart failure. Results of the Cooperative North Scandinavian Enalapril Survival Study (CONSENSUS). $N$ Engl $f$ Med 1987;316: 1429-35. 
2 Collins R, Julian D. British Heart Foundation surveys (1987 and 1989) of United Kingdom treatment policies for acute myocardial infarction. Br Heart $\mathcal{f} 1991 ; 66$ : 250-5.

3 De Vita C, Franzosi MG, Geraci E, Maggioni AP, Mauri F, Mezzanotte G, et al. GISSI-2: mortality plus extensive left-ventricular damage as "end-point" (letter). Lancet 1990;335:289.

4 Hall AS, Tan LB, Ball SG. Inhibition of ACE/kininase-II, acute myocardial infarction, and survival. Cardiovasc Res acute myocardial in

5 Hutchins GM, Bulkley BH. Infarct expansion versus extension: two different complications of acute myocardial infarction. Am f Cardiol 1978;41:1127-32.

6 ISIS-4 Collaborative Group. Fourth International Study of Infarct Survival (ISIS-4): a randomised factorial trial assessing early oral captopril, oral mononitrate, and intravenous magnesium sulphate in 58,050 patients with suspected acute myocardial infarction. Lancet 1995;345: 669-85.

7 Gruppo Italiano per lo Studio della Sopravvivenza nell'infarcto Miocardico. GISSI-3: effects of lisinopril and transdermal glyceryl trinitrate singly and together on 6-week mortality and ventricular function after acute myocardial infarction. Lancet 1994;343:1115-22.

8 Ambrosioni E, Borghi C, Magnani B. The Survival of Myocardial Infarction Long-term Evaluation (SMILE) Study Investigators. The effect of the angiotensin-converting-enzyme inhibitor zofenopril on mortality and morbidity after anterior myocardial infarction. $N$ Engl $f$ Med 1995;332:80-5.

9 Oral captopril versus placebo among 13,634 patients with suspected acute myocardial infarction: interim report suspected acute myocardial infarction: interim report
from the Chinese Cardiac Study (CCS-1). Lancet from the Chin

10 Swedberg K, Held P, Kjekshus J, Rasmussen K, Ryden L, Wedel $\mathrm{H}$. Effects of the early administration of enalapril on mortality in patients with acute myocardial infarction Results of the Cooperative New Scandinavian Enalapri Survival Study II (CONSENSUS II). $N$ Engl $f$ Med 1992;327:678-84.

11 Pfeffer MA, Braunwald E, Moye LA, Basta L, Brown EJ, Cuddy TE, et al. The SAVE Investigators. Effect of captopril on mortality and morbidity in patients with lef ventricular dysfunction after myocardial infarction. Results of the survival and ventricular enlargement trial $N$ Engl f Med 1992;327:669-77.

12 The Acute Infarction Ramipril Efficacy (AIRE) Study Investigators. Effect of ramipril on mortality and morbidity of survivors of acute myocardial infarction with clinica evidence of heart failure. Lancet 1993;342:821-8.

13 The Trace Study Group. The Trandolapril Cardiac Evaluation (TRACE) study: rationale, design, and baseline characteristics of the

14 The Trace Study Group. Oral presentation at World Congress of Cardiology, Berlin, 1994.

15 Latini R, Maggioni AP, Zuanetti G, Franzosi MG,
Tognoni G on behalf of the GISSI-3 investigators. ACE inhibitors post-MI: the case for early, nonselective treatment. Controversies in Cardiology 1995;6:9-12.

16 Furberg CD, Yusuf S. Effect of vasodilators on survival in chronic congestive heart failure. Am $\mathcal{F}$ Cardiol 1985;55: 1110-3.

17 van Gilst WH, de Graeff PA, Kingma JH, Wesseling H, de Langen CD. Captopril reduces purine loss and reperfu-
sion arrhythmias in the rat heart after coronary artery sion arrhythmias in the rat heart after coron
occlusion. Eur 7 Pharmacol 1984;100:113-7.

18 de Graeff PA, van Gilst WH, de Langen CD, Kingma JH, Wesseling $\mathrm{H}$. Concentration-dependent protection by captopril against ischaemia-reperfusion injury in the isolated rat heart. Arch Int Pharmacodyn Ther 1986;280 $181-93$

19 The SOLVD Investigators. Effect of enalapril on survival in patients with reduced left ventricular ejection fractions and congestive heart failure. $N$ Engl f Med 1991;325 293-302.

20 The SOLVD Investigators. Effect of enalapril on mortality and the development of heart failure in asymptomatic patients with reduced left ventricular ejection fraction [published erratum appears in $N \mathrm{Engl} f \mathrm{~J}$ Med 1992;327:1768]. N Engl F Med 1992;327:685-91.

21 Furberg CD, Campbell RW, Pitt B. ACE-inhibitors after myocardial infarction [letter]. $N$ Engl $f$ Med 1993;328 967-9.

22 Ganley CJ, Hung HM, Temple R. More on the survival and ventricular enlargement trial [letter; comment]. $N$ Engl F Med 1993;329:1204-6.

23 GISSI-3 Investigators. Oral presentation at World Congress of Cardiology, Berlin, 1994.

24 Pfeffer MA, Lamas GA, Vaughan DE, Parisi AF, Braunwald E. Effect of captopril on progressive ventricular dilatation after anterior myocardial infarction. $N$ Engl $f$ Med 1988;319:80-6.

25 Pfeffer MA, Pfeffer JM, Steinberg C, Finn P. Survival after an experimental myocardial infarction: beneficial effects of long-term therapy with captopril. Circulation 1985 72:406-12.

26 Sharpe N, Murphy J, Smith H, Hannan S. Treatment of patients with symptomless left ventricular dysfunction after myocardial infarction. Lancet 1988;i:255-9.

27 Hall AS. Clinical trials versus actual practice. In: Ball SG, ed. Myocardial infarction: from trials to practice. Petersfield, UK: Wrightson Biomedical Publishing Ltd, 1995.

28 Tognoni G. On behalf of the Gruppo Italiano per lo Studio della Sopravvivenza nell'Infarcto Micardico [letter]. Lancet 1994;343:1633-4.

29 Hall AS, Ball SG. Update on the use of ACE-inhibition therapy after acute myocardial infarction. Exp Opin Invest Drugs 1995;4:143-6.

30 Weisman HF, Healy B. Myocardial infarct expansion, infarct extension, and reinfarction: pathophysiologic concepts. Prog Cardiovasc Dis 1987;30:73-110.

31 Hall AS, Ball SG. Clinical background to the use of ACE-inhibitor therapy after myocardial infarction. $\mathcal{F}$ Cardiovascular Risk 1995;2:396-405. 